\title{
VN Quantum Dots Anchored Uniformly onto Nitrogen-Doped Graphene as Efficient Electrocatalysts for Oxygen Reduction Reaction
}

\author{
Jing Wang, Lan Wang and Shubin Yang* \\ Key Laboratory of Aerospace Advanced Materials and \\ Performance of Ministry of Education \\ School of Materials Science and Engineering \\ Beihang University \\ Beijing 100191, P. R. China \\ *yangshubin@buaa.edu.cn
}

Received 16 February 2018

Accepted 23 March 2018

Published 17 April 2018

\begin{abstract}
A new type of vanadium nitride quantum dots anchored homogeneously onto nitrogen-doped graphene (VNQD-NG) is fabricated as nonprecious metal-based electrocatalysts for ORR via a combined hydrothermal and ammonia annealing process. The unique structural features of VNQD-NG including plentiful VN quantum dots with the sizes of $3-6 \mathrm{~nm}$, high surface area and multi-level pores afford considerable structural edges and defects as active sites, maximizing the exposed active sites and providing sufficient electron transport pathways for ORR. Hence, the optimized VNQD-NG exhibits high electrocatalytic activity, long durability and high selectivity for ORR, better than commercially available Pt-C.
\end{abstract}

Keywords: VN; quantum dots; ORR electrocatalysis; nitrogen-doped graphene.

\section{Introduction}

Developing suitable electrocatalysts for the oxygen reduction reactions (ORR) is significant in the practical applications of fuel cells and metal-air batteries due to the kinetic sluggishness of ORR with a complex four-electron transfer process. ${ }^{1-9}$ Despite the high efficiency of platinum $(\mathrm{Pt})$ and Pt-based alloys for ORR, their high cost along with the rare reserves in nature largely impedes the largescale practical application. ${ }^{10-14}$ Therefore, developing low-cost nonprecious metal-based catalysts as an alternative to Pt-based catalysts is crucial in the fields of fuel cells and metal-air batteries.
Very recently, some transition metal compounds such as transition metal oxides $\left(\mathrm{FeO}_{x},{ }^{15-17}\right.$ $\left.\mathrm{XCO}_{2} \mathrm{O}_{4},{ }^{18,19} \quad \mathrm{Co}_{3} \mathrm{O}_{4}{ }^{20-23}\right)$, sulfides $\left(\mathrm{CoS}_{x},{ }^{24}\right.$ $\left.\mathrm{MoS}_{2},{ }^{25,26}\right), \mathrm{CuSe}^{27}$ and nitrides $\left(\mathrm{W}_{x} \mathrm{~N},{ }^{28,29} \mathrm{MoN},{ }^{30,31}\right.$ $\mathrm{NG}^{32}$ ) have been proposed as ORR electrocatalysts owing to their abundance in nature, chemical stability and intrinsic electrocatalytic activities for hydrogen and oxygen. In particular, transition metal nitrides possess a greater density of states around Fermi level in comparison with corresponding transition metal, which renders them to have attractive electrocatalytic activities for ORR, analogous to those of Pt-based catalysts. For instance, $\mathrm{W}_{2} \mathrm{~N}$ and MoN supported on carbons have 
been explored via temperature-programmed reaction (TPR) approaches and demonstrated the obvious catalytic activities and good stabilities over $60 \mathrm{~h}$ for ORR by testing in a typical single fuel cell setup, despite the low onset potentials $(\sim 0.6 \mathrm{~V}$ versus RHE). ${ }^{28,30}$ In comparison, vanadium nitrite (VN) not only has the similar structure and high density of states to those of the above transition-metal nitrides, but also shows good corrosion resistance and high electrical conductivity $\left(1.67 \times 10^{6} \Omega^{-1} \mathrm{~m}^{-1}\right)$, holding great promise as an active electrocatalyst for ORR. Unfortunately, few $\mathrm{VN}$ has been investigated with regard to ORR to date, despite that $\mathrm{VN}$ has been explored for supercapacitors ${ }^{33-36}$ and lithium-ion batteries. ${ }^{37-41}$

In this work, a new type of vanadium nitride quantum dots anchored homogeneously onto nitrogen-doped graphene (denoted as VNQD-NG) is fabricated as efficient ORR electrocatalyst by a simple hydrothermal method of $\mathrm{NH}_{4} \mathrm{VO}_{3}$ and graphene oxide, as well as subsequent ammonia annealing process at different temperatures. The as-prepared VNQD-NG possesses numerous zerodimensional (0D) VN quantum dots (QDs) with the sizes of $3-6 \mathrm{~nm}$ anchored homogeneously onto the surface of nitrogen-doped graphene, affording considerable structural edges and defects as active sites for ORR. Moreover, the VNQD-NG nanosheets can simultaneously construct a three-dimensional (3D) porous architecture to maximize the exposed active sites and provide sufficient electron transport pathways during ORR. Eventually, the optimized VNQD-NG exhibits high electrocatalytic activity, long durability and high selectivity for ORR, superior to commercially available Pt-C.

\section{Experimental Methods}

\subsection{Synthesis of VNQD-NG}

In a typical experiment, $160 \mathrm{mg} \mathrm{NH}_{4} \mathrm{VO}_{3}$ (A. R.) was well dissolved in $8 \mathrm{~mL}$ of graphene oxide aqueous solution $\left(2 \mathrm{mg} \mathrm{mL}^{-1}\right)$ prepared with graphite flakes via the modified Hummers method. After that $2 \mathrm{~mL} \mathrm{NH} \mathrm{H}_{2} \mathrm{O}$ (28 wt.\%, A.R.) was added. Then the above dispersion was transferred into a Teflonlined stainless-steel autoclave $(50 \mathrm{~mL}$ capacity) and held in an oven at $180^{\circ} \mathrm{C}$ for $12 \mathrm{~h}$. After completion of the reaction, the resultant hydrogel was dehydrated through the freeze-drying method to maintain its 3D architecture. Then it was annealed in ammonia ( $150 \mathrm{sccm})$ mixed with nitrogen $(450 \mathrm{sccm})$ atmosphere for $2 \mathrm{~h}$ at $500^{\circ} \mathrm{C}, 600^{\circ} \mathrm{C}$ and $700^{\circ} \mathrm{C}$, respectively (the corresponding products are named as VNGD-NG-500, VNGD-NG-600 and VNGD-NG-700, respectively). In contrast, the NG600 prepared without $\mathrm{NH}_{4} \mathrm{VO}_{3}$ in ammonia aqueous solution with the same method and platinum load carbon electrode (commercial Pt-C, 10 wt.\% platinum on carbon black) were prepared as control samples.

\subsection{Materials characterization}

The morphology and microstructure of VNQD-NG were investigated via FE-SEM (JSM 7500, JEOL, Japan), TEM, HRTEM (Tecnai G2 F20 U-TWIN), XRD (Rigaku D/max2500PC), and XPS (ESCALAB 250, Thermo Electron) measurements. Nitrogen adsorption-desorption isotherms and specific surface area were measured on Quantachrome analyzer (QDS-MP-30, USA) at $77 \mathrm{~K}$. The mass content of samples were analyzed by Vario EL cube (Elementar, Germany).

\subsection{Electrochemical measurements}

Typically, $2 \mathrm{mg}$ VNQD-NG samples were dispersed in $1 \mathrm{~mL}$ solvent mixture of $5 \%$ Nafion solution, Dimethylcarbinol and water (the volume ratio is $2: 3: 15$ ), and then sonicated. $20 \mu \mathrm{L}$ of the dispersion was dropped onto a polished glass carbon (GC) electrode and dried in air overnight to obtain a smooth and well-distributed film. A CHI760E (CHI instrument, USA) potentiostat equipment coupled with a RRDE-E7R9 apparatus (PINE) was installed for the measurement. The electric measurements were proceeded at room temperature in an $\mathrm{O}_{2}$ (or $\mathrm{N}_{2}$ as a contrast)-saturated $\left(40 \mathrm{~mL} \mathrm{~min}^{-1}\right) 0.1 \mathrm{M} \mathrm{KOH}$ electrode using a typical three-electrode system: $\mathrm{Pt}$ ring/GC disk working electrode (PINE Instrument, GC diameter: $5.61 \mathrm{~mm}$, Pt ring inner diameter: $6.25 \mathrm{~mm}$ and outer diameter: $7.92 \mathrm{~mm})$, Pt wire counter electrode and $\mathrm{Ag} / \mathrm{AgCl}$ (10\% KCl-filled) reference electrode. $\mathrm{CV}$ tests were performed from $0.2 \mathrm{~V}$ to $-1.2 \mathrm{~V}$ at a scan rate of $100 \mathrm{mV} \mathrm{s}^{-1}$ in an $\mathrm{O}_{2}$-satured or $\mathrm{N}_{2}$-deaerated electrolyte. RRDE linear sweep voltammetry measurements were conducted from $0.2 \mathrm{~V}$ to $-1.2 \mathrm{~V}$ in an $\mathrm{O}_{2}$-saturated under different rotation rates (100-2025 rpm) at a sweep rate of $5 \mathrm{mV} \mathrm{s}^{-1}$. The durability and methanol-poisoning test were executed in $0.1 \mathrm{M}$ oxygensaturated $\mathrm{KOH}$ electrolyte under a rotation rate of $1600 \mathrm{rpm}$ at an electrode potential of $-0.3 \mathrm{~V}$. 


\section{Results and Discussion}

Porous 3D networks are built from large quantities of nanosheets with the sizes of a few micrometers [Figs. 1(a) and 1(b)]. And as revealed in Fig. 1(c), numerous 3-6 nm quantum dots are anchored uniformly and tightly onto the thin-layered graphene sheets. The lattice spacing of quantum dots is approximately $0.206 \mathrm{~nm}$ discovered by the HRTEM image [Fig. 1(d)], in good accordance with the (200) facet of VN. The selected area electron diffraction (SAED) validated that the VNQD-NG is polycrystalline [Fig. 1(c), inset]. Furthermore, the grain size of VNQD could be modulated from $2 \mathrm{~nm}$ to $7 \mathrm{~nm}$ by raising the calcination temperature from $500^{\circ} \mathrm{C}$ to $700^{\circ} \mathrm{C}$. Additionally, all elements (C, N, V and O) evenly dispersed onto the graphene nanosheets were examined by the scanning transmission electron microscopy annular dark field (STEM-ADF) image and elemental mappings [Figs. 1(e)-1(h)].
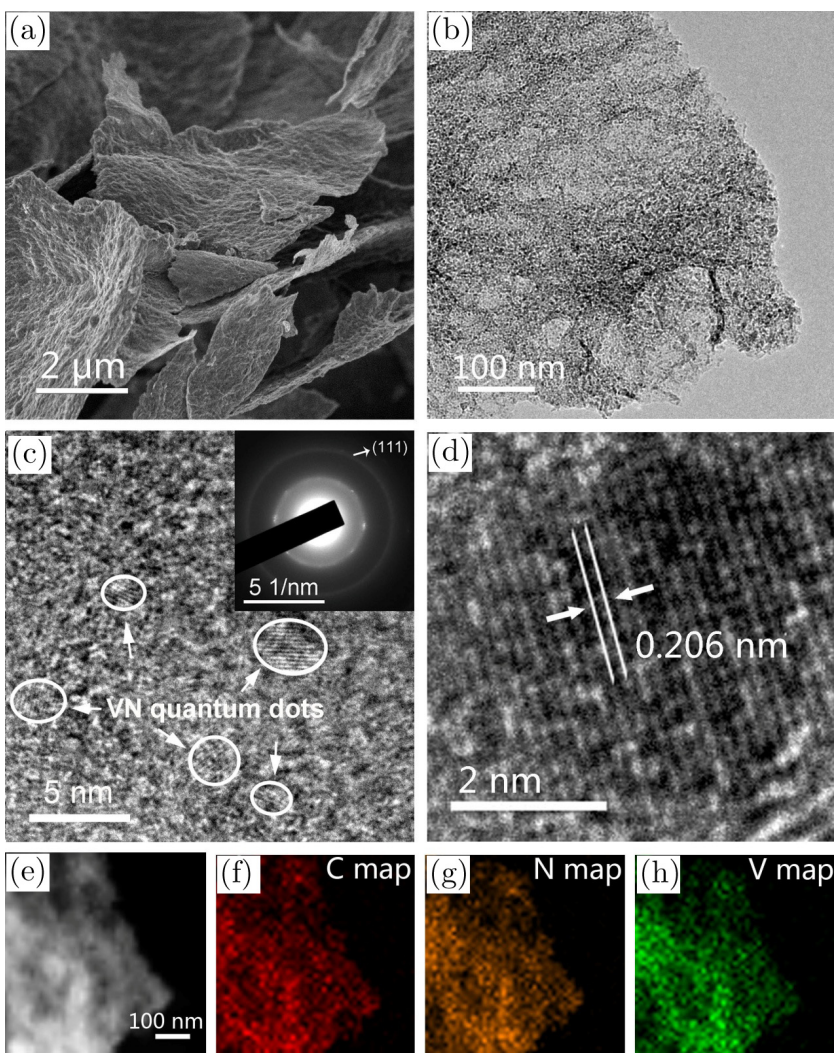

Fig. 1. (a) Typical SEM images of VNQD-NG-600. Representative (b) TEM and (c, d) HRTEM images of VNQD-NG600 , revealing quantum dots level of $1-5 \mathrm{~nm}$ homogeneously and tightly anchored on thin-layered graphene sheets. The inset in (c) is the corresponding SAED patterns. (e) STEM ADF image of VNQD-NG-600 and the corresponding element mappings: (f) $\mathrm{C}$, (g) $\mathrm{N}$ and (h) V.
To determine the crystalline structure of VNQDNG, X-ray diffraction (XRD) analysis was carried out [Fig. 2(a)]. Apparently, the major peaks were indexed to the face-centered cubic VN characteristic peak corresponding the card JCPDS 73-0528, which was consistent with the HRTEM characterization. The residual broad shoulder (002) centered at around $26^{\circ}$ arises from the stacked graphene nanosheets. The stronger diffraction peaks of VN appear in the XRD patterns with the increase of calcination temperature, manifesting more well-ordered VN structure formed at higher temperature. On the basis of nitrogen adsorption-desorption analysis, the measured Brunauer-Emmett-Teller (BET) specific surface area values of VNQD-NG500, VNQD-NG-600 and VNQD-NG-700 (abbreviation of VNQD-NG with $500^{\circ} \mathrm{C}, 600^{\circ} \mathrm{C}$ and $700^{\circ} \mathrm{C}$ annealing temperature) are $20.2 \mathrm{~m}^{2} \mathrm{~g}^{-1}, 31.5 \mathrm{~m}^{2} \mathrm{~g}^{-1}$ and $60.7 \mathrm{~m}^{2} \mathrm{~g}^{-1}$, respectively [Fig. 2(b)]. The pore size distribution of all samples is in the range from $3 \mathrm{~nm}$ up to $20 \mathrm{~nm}$ [Fig. 2(c)]. The hysteresis loop of nitrogen adsorption and desorption curve becomes more obvious with the increasing annealing temperature, due to the slight collapse of graphene and etching of edge active sites around pores caused by the high temperature, demonstrating the existence of more mesoporous, which further facilitated the ORR catalytic performance.

The elemental composition and content of the VNQD-NG were investigated by X-ray photoelectron spectra (XPS) (Fig. 3). It is found that there are approximately $9-13 \mathrm{wt} . \% \mathrm{~N}$ atom and $35-48 \mathrm{wt} . \%$ $\mathrm{C}$ atom in the VNQD-NG series. Apparently, the survey scan spectra of XPS manifest the presences of $\mathrm{C} 1 \mathrm{~s}, \mathrm{~N} 1 \mathrm{~s}, \mathrm{~V} 2 \mathrm{p}$ and O1s without any other impurities for the VNQD-NG series [Fig. 3(a)]. As shown in Fig. 3(b) there are three different types of vanadium existed, which can be defined as $\mathrm{VN}, \mathrm{VO}_{2}$ and $\mathrm{V}_{2} \mathrm{O}_{5}$ in surface oxides at $514.7 \mathrm{eV}, 516.7 \mathrm{eV}$ and $517.4 \mathrm{eV}$, respectively. ${ }^{42}$ The high-resolution $\mathrm{N} 1 \mathrm{~s}$ spectrum located at $397.0 \mathrm{eV}, 398.3 \mathrm{eV}$, $399.7 \mathrm{eV}$ and $401.4 \mathrm{eV}$ could be fitted to typical N-V bond, pyridinic-N, pyrrolic- $\mathrm{N}$ and graphitic-N, respectively [Fig. 3(c)]. ${ }^{43-45} \mathrm{In}$ addition, the $\mathrm{C} 1 \mathrm{~s}$ signals show the presence of graphitic carbon and $\mathrm{C}-\mathrm{N}$ bond in the aromatic structure, while the O1s peak is assigned to metal oxide and terminal hydroxyl groups owing to the passivated protective layer on the surface, further enhancing the stability of catalyst for ORR [Figs. 3(d) and 3(e)]. ${ }^{41,46,47}$ With enhancing the annealing temperature, the contents of 


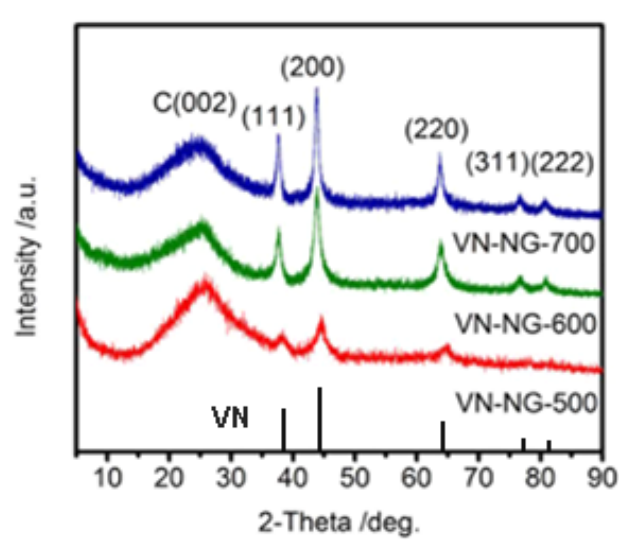

(a)

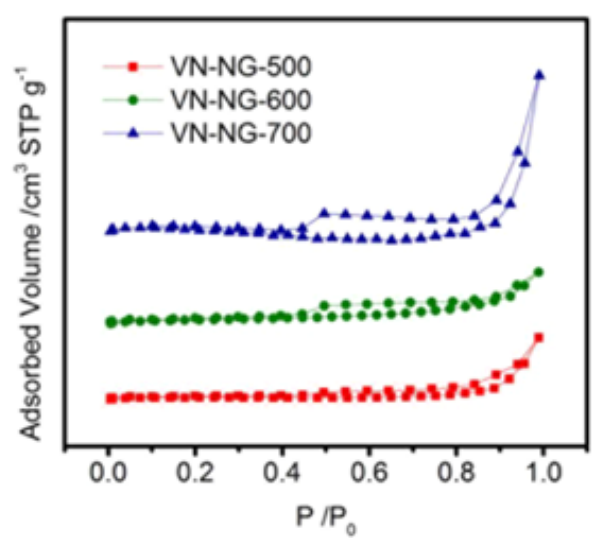

(b)

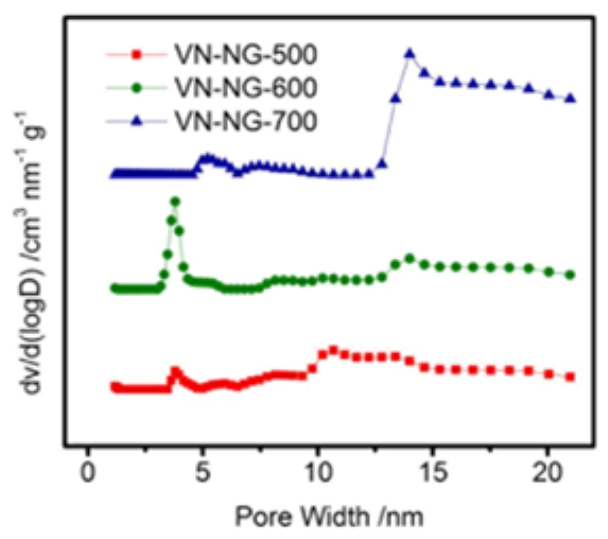

(c)

Fig. 2. (a) XRD patterns; (b) Nitrogen adsorption/desorption isotherms; and (c) pore size distribution of VNQD-NG-500, VNQDNG-600 and VNQD-NG-700, disclosing the pore size distribution from $3 \mathrm{~nm}$ to $20 \mathrm{~nm}$.

$\mathrm{V}-\mathrm{N}$ bond increase gradually, consistent with the XRD analysis, which should be a vital influence factor for the ORR electrocatalytic performances.

To investigate the ORR characteristics of VNQD-NG samples, cyclic voltammogram (CV) measurements were executed in an aqueous $0.1 \mathrm{M}$ $\mathrm{KOH}$ solution. VNQD-NG-600 exhibits a pronounced cathodic peak at $-0.2 \mathrm{~V}$ in $\mathrm{O}_{2}$-saturated electrolyte, whereas no evident peak occurs between $0.2 \mathrm{~V}$ and $-1.2 \mathrm{~V}$ in $\mathrm{N}_{2}$-saturated electrolyte [Fig. 4(a)], reflecting a prominent electrocatalytic activity of the VNQD-NG for oxygen reduction. To further evaluate the selectivity of VNQD-NG, chronoamperometric measurements were carried out. A strong current response occurs at Pt-C catalyst when $3 \mathrm{M}$ methanol was injected in oxygensaturated solution, whereas the VNQD-NG maintains a stable current without any distinct response [Fig. 4(b)]. Apparently, the VNQD-NG hybrid exhibits a high selectivity to methanol in the alkaline electrolyte, tolerance to crossover effects causing by fuel molecules permeating through the polymer membrane.

The rotating ring-disk electrode (RRDE) measurements were conducted to verify the ORR electrochemical kinetics of VNQD-NG, meanwhile NG-600 and Pt-C were tested as a contrast [Figs. 5(a) and 5(b)]. The ORR onset potential of VNQD-NG500, VNQD-NG-600 and VNQD-NG-700 are at $-0.15 \mathrm{~V},-0.10 \mathrm{~V}$ and $-0.08 \mathrm{~V}$, respectively, close to that of Pt-C catalyst. Interestingly, the onset potential and half-wave potential shift to the more positive direction, and much lower ring current is visible by increasing the heating temperature from $500^{\circ} \mathrm{C}$ to $700^{\circ} \mathrm{C}$. This should be ascribed to the increasing $\mathrm{V}-\mathrm{N}$ bonds formed at the higher annealing temperatures. In addition, the electron transfer number $(n)$ and kinetic-limiting current density $\left(J_{\mathrm{k}}\right)$ 
(a)

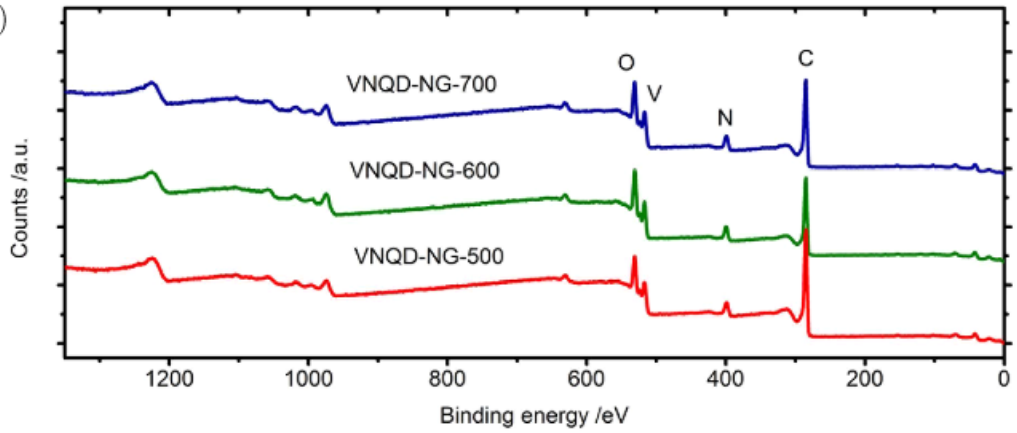

(b)

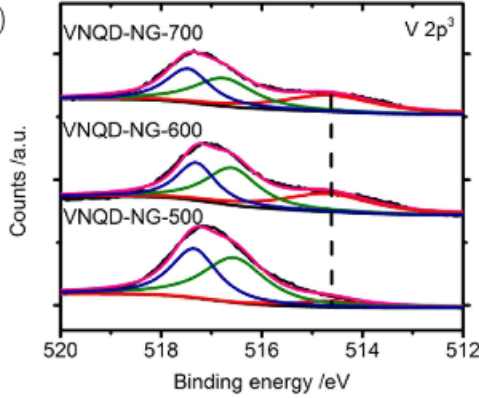

(d)

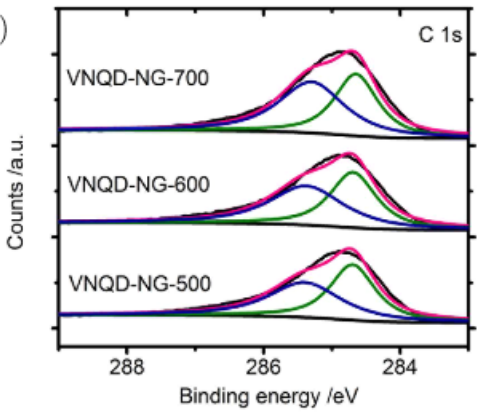

(c)

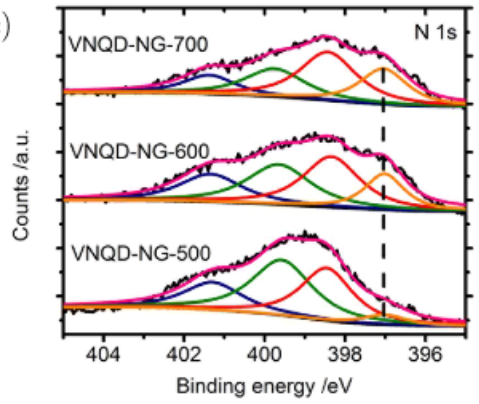

(e)

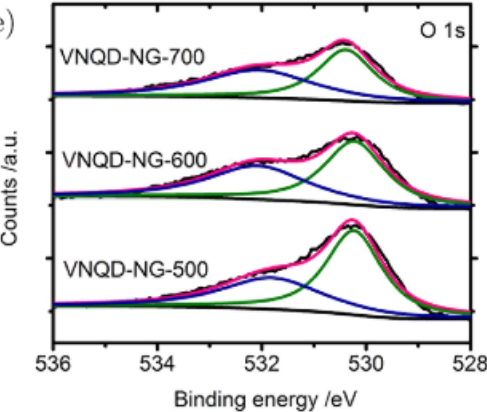

Fig. 3. (a) XPS survey spectra, manifesting the presences of C1s, N1s, V2p and O1s, (b-d) High-resolution XPS spectra of VNQDNG-500, VNQD-NG-600 and VNQD-NG-700: (b) V 2p ${ }^{3}$, the peak at $514.7 \mathrm{eV}$ fitted to $\mathrm{V}^{3+}$ in VN; (c) N1s, the high-resolution N1s peak at $397.0 \mathrm{eV}$ defined as $\mathrm{N}-\mathrm{V}$ bond; (d) high-resolution $\mathrm{C} 1 \mathrm{~s}$; (e) O1s.

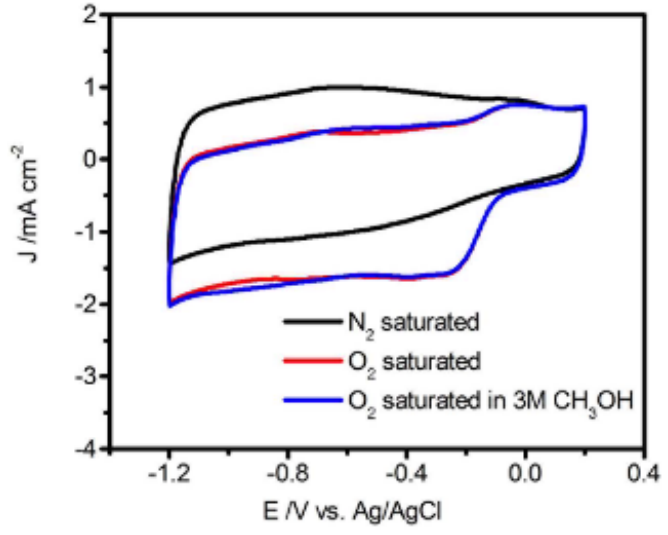

(a)

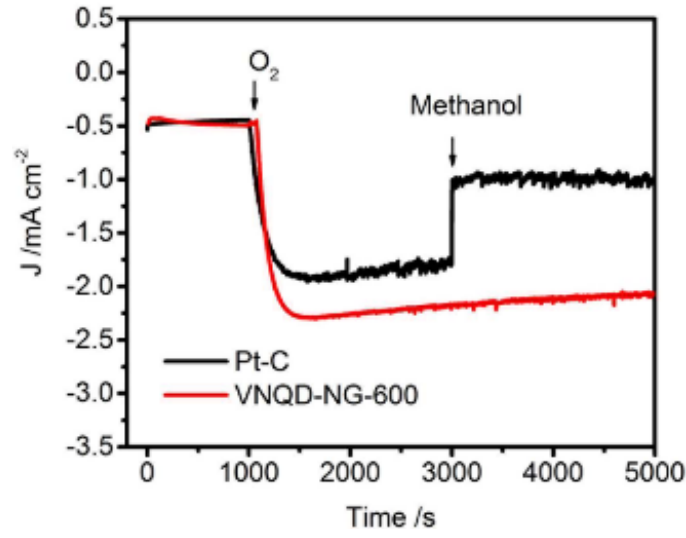

(b)

Fig. 4. Electrocatalytic activities of VNQD-NG as oxygen reduction catalysts. (a) CVs of VNQD-NG-600 in $0.1 \mathrm{M}$ KOH electrolyte with $\mathrm{N}_{2}$-saturated, $\mathrm{O}_{2}$-saturated and $\mathrm{O}_{2}$-saturated in $3 \mathrm{M}$ methanol; (b) Current-Time $(i-t)$ chronoamperometric responses of VNQD-NG-600 and commercial Pt-C electrode at $-0.3 \mathrm{~V}$ followed by introduction of $\mathrm{O}_{2}$ and methanol $(3 \mathrm{M})$. 


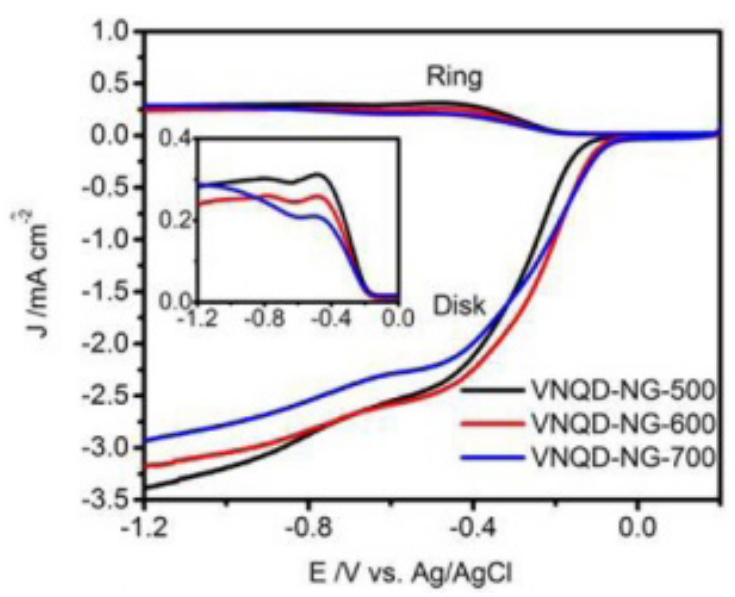

(a)

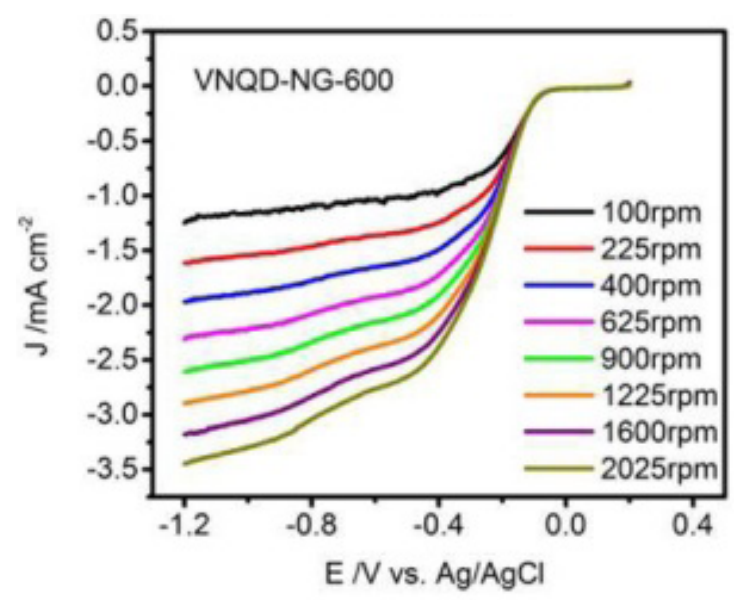

(c)

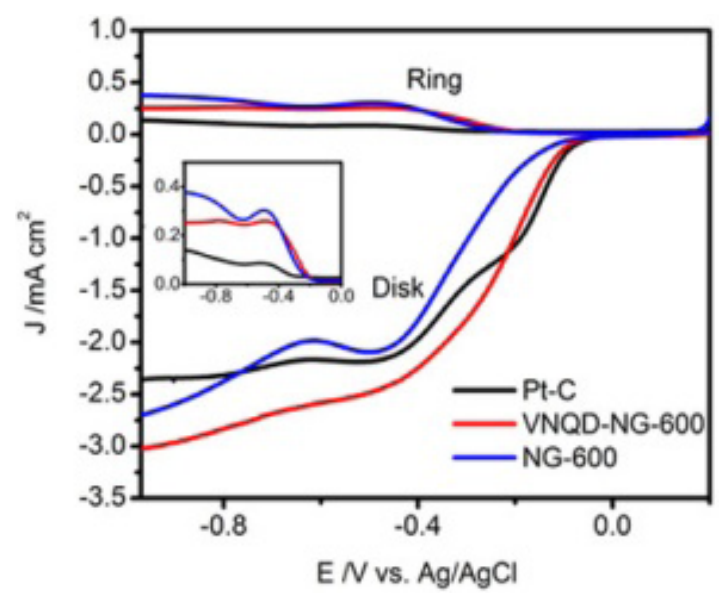

(b)

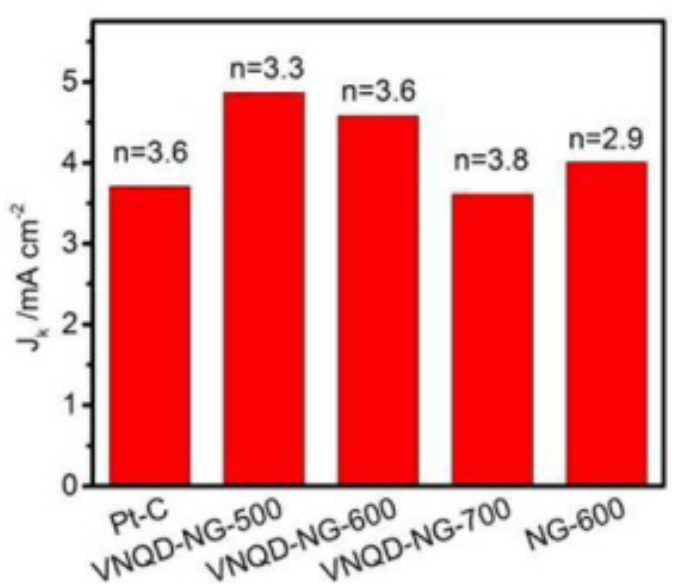

(d)

Fig. 5. RRDE curves of (a) VNQD-NG-500, VNQD-NG-600, and VNQD-NG-700; (b) commercial Pt-C, VNQD-NG-600 and NG600 at a rotation speed of $1600 \mathrm{rpm}$ (inset: magnified Ring current); (c) VNQD-NG-600 with different RRDE rotation speeds (in rpm). (d) Comparison of electrochemical activity for commercial Pt-C, VNQD-NG-500, VNQD-NG-600, VNQD-NG-700 and NG600 at $-0.50 \mathrm{~V}$.

were analyzed in terms of Eq. (1), and KoutechyLevich (K-L) equations [Figs. 5(c) and 5(d)].

$$
n=4 I_{D} /\left(I_{D}+I_{R} / N\right)
$$

where $N=0.371$ is the current collection efficiency, $I_{D}$ and $I_{R}$ represent the disk current and ring current, respectively. Typically, in the case of VNQD-NG-500, a kinetic-limiting current density $\left(J_{\mathrm{k}}\right)$ of $4.8 \mathrm{~mA} \mathrm{~cm}^{-2}$ is achieved, higher than that of commercial Pt-C $\left(3.7 \mathrm{~mA} \mathrm{~cm}^{-2}\right)$ and NG-600 $\left(4.0 \mathrm{~mA} \mathrm{~cm}^{-2}\right)$. And it is comparable to that of $\mathrm{N}, \mathrm{S}$,O-doped carbon $\left(3.8 \mathrm{~mA} \mathrm{~cm}^{-2}\right),{ }^{48} \mathrm{MOF}$ derived carbon $\left(4.2 \mathrm{~mA} \mathrm{~cm}^{-2}\right),{ }^{49} \mathrm{rGO} / \mathrm{MnO}_{2} / \mathrm{Ag}(3.4 \mathrm{~mA}$ $\left.\mathrm{cm}^{-2}\right)^{50}$ and $\mathrm{Fe}_{3} \mathrm{C} @ \mathrm{NCNF}-\mathrm{X} \quad\left(4.51 \mathrm{~mA} \mathrm{~cm}^{-2}\right)^{51}$ (Table 1). With increasing annealing temperature
Table 1. Comparison of the electrocatalytic activity and kinetic parameters of the catalysts in ORR.

\begin{tabular}{|c|c|c|}
\hline Samples & $\begin{array}{l}\text { Kinetic-limiting } \\
\text { current density } \\
\left(J_{\mathrm{k}} / \mathrm{mA} \mathrm{cm}^{-2}\right)\end{array}$ & $\begin{array}{c}\text { Electron } \\
\text { transfer } \\
\text { number }(n)\end{array}$ \\
\hline VNQD-NG & 4.8 & 3.8 \\
\hline NG-600 & 4.0 & 2.6 \\
\hline $\mathrm{Pt}$ & 3.7 & 3.6 \\
\hline N,S,O-doped carbon ${ }^{48}$ & 3.8 & 3.5 \\
\hline vanadium carbonitride ${ }^{40}$ & - & $1.8-3.4$ \\
\hline MOF derived carbon ${ }^{49}$ & 4.2 & 3.12 \\
\hline $\mathrm{rGO} / \mathrm{MnO}_{2} / \mathrm{Ag}^{50}$ & 3.4 & 4 \\
\hline $\mathrm{Fe}_{3} \mathrm{C} @ \mathrm{NCNF}-\mathrm{X}^{41}$ & 4.51 & 3.8 \\
\hline $\mathrm{Mn}_{3} \mathrm{O}_{4} / \mathrm{MXene}^{52}$ & 8.7 & 3.4 \\
\hline
\end{tabular}


from $500^{\circ} \mathrm{C}$ to $700^{\circ} \mathrm{C}$, the electron transfer number of VNQD-NG increases from 3.3 to 3.8 with the maximum value of 3.8 , owing to the more well-ordered VN and the increasing contents of $\mathrm{V}-\mathrm{N}$ bond, demonstrating electrocatalytic activity of VNQD-NG greatly accompanied by the annealing temperature. This maximum value is much higher than that of $\mathrm{NG}$ (2.9), VNQD-NG-500 (3.3) and VNQD-NG-600 (3.6) as well as reported for N,S,O-doped carbon $(3.5),{ }^{48}$ vanadium carbonitride $(1.8-3.4),{ }^{40} \mathrm{MOF}$ derived carbon $(3.12)^{49}$ and $\mathrm{Mn}_{3} \mathrm{O}_{4} /$ MXene (3.4), ${ }^{52}$ indicating a better catalysis of VNQD-NG samples than other non-Pt catalysts (Table 1 ). The excellent performance should be related to the ultra-small VN quantum dots and superior electrical conductivity. Representatively, the VN quantum dots are tightly anchored on the porous 3D graphene sheets which makes much closer interfacial contact, providing good electronic conductivity and facilitating the fast transportation of $\mathrm{O}_{2}$. Thus, these structural features can significantly promote the electrocatalytic activity of VNQD-NG for ORR.

Since durability is an important factor in present fuel cell technology, the stability of VNQD-NG and commercial Pt-C were further tested at $-0.3 \mathrm{~V}$ with $\mathrm{O}_{2}$-saturated for $30000 \mathrm{~s}$. Note that the currenttime $(i-t)$ choronoamperometric response for VNQD-NG reveals a high current density retention of $77 \%$ after $30000 \mathrm{~s}$, which is superior to that of commercial Pt-C (60\%) (Fig. 6). The attenuation should be attributed to the catalyst detachment from cathode after long-term testing. Remarkably, the durability of VNQD-NG ascribes to the tight

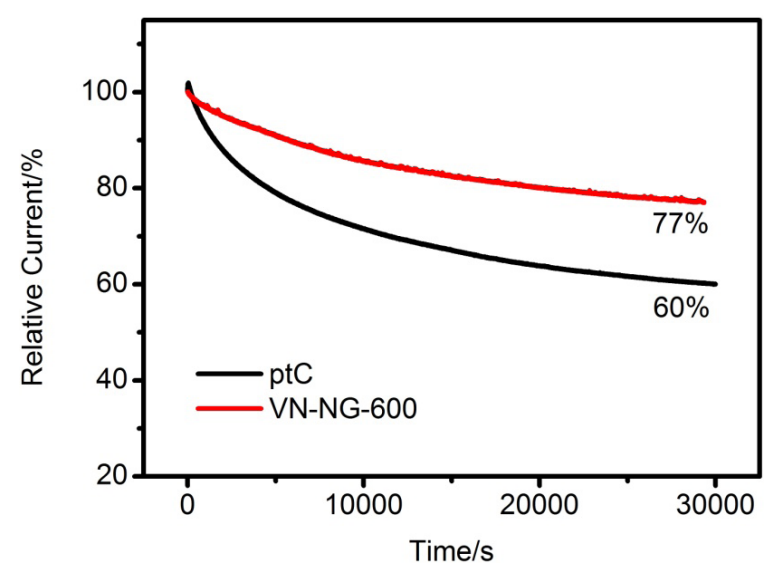

Fig. 6. Current-Time $(i-t)$ chronoamperometric responses of VNQD-NG-600 and commercial Pt-C at $-0.3 \mathrm{~V}$ in $\mathrm{O}_{2}$-saturated $0.1 \mathrm{M} \mathrm{KOH}$ electrode at a rotation rate of $1600 \mathrm{rpm}$. anchoring of ultrafine VN quantum dots on graphene and the stability of VNQDs, which leads to intense interfacial contact, maintained the structural integrity, as well as restrained the pulverization and collapse.

Overall, based on the aforementioned electrocatalytic studies, we speculated that the VNQDs may act as the dominated ORR active sites of the VNQD-NG catalyst when compared with NG. The excellent activity of the VNQDs may be due to the presence of nitrogen atoms, which can lead to the shrinkage of d-band, thus increasing the electron density near the Fermi level of VN, and further improving the reduction rate of the adsorbed oxygen atoms. ${ }^{53}$ Furthermore, it is suggested that the introduction of nitrogen atom may weaken the strong adsorption of vanadium toward ORR intermediates (such as $\mathrm{OH}, \mathrm{O}$ and $\mathrm{OOH}$ ). In addition, the nitrogen doped in graphene also negative charged the adjacent carbon atoms, which also benefit the ORR activity of the VNQD-NG catalyst. ${ }^{54}$ Therefore, associated with the unique structure and morphology of the VNQD-NG samples, such enhanced electrocatalytic performance can be ascribed to the following aspects: (1) abundant ORR active sites such as VNQDs, (2) the special 0D-3D architecture with high surface area and multi-level pores facilitate the fast transport of $\mathrm{O}_{2}$ (3) the existence of high conductivity $\mathrm{N}$-doped graphene benefit the electron transportation, (4) the VN quantum dots are tightly anchored on the porous $3 \mathrm{D}$ graphene sheets, which may contribute to the durability of ORR.

\section{Conclusion}

In conclusion, we have successfully demonstrated $3 \mathrm{D}$ porous VNQD-NG as nonprecious metal-based electrocatalysts for ORR via a simple hydrothermal and ammonia annealing process. The unique structural features of VNQD-NG including the plentiful VN quantum dots, high surface area and multi-level pores are favorable for the ORR. Hence, VNQDNG-600 exhibits high electrocatalytic activity, long durability and high selectivity for ORR, better than commercially available Pt-C. These achievements could provide an extension of developing various other 3D porous metal nitride quantum dots onto graphene for broad applications in sensors, catalysis and other electronic devices. 


\section{Acknowledgment}

This work was financially supported by National Science Foundation of China (No. 51572007), the Scientific Research Foundation for the Returned Overseas Chinese Scholars (No. 37-7290-01), State Education Ministry, the "Recruitment Program of Global Experts".

\section{References}

1. K. Gong, F. Du, Z. Xia, M. Durstock and L. Dai, Science 323, 760 (2009).

2. H. Zhang, Y. Niu and W. Hu, J. Colloid Interface Sci. 505, 32 (2017).

3. A. Morozan, B. Jousselme and S. Palacin, Energy Environ. Sci. 4, 1238 (2011).

4. Y. Cai, P. Gao, F. Wang and H. Zhu, Electrochim. Acta 245, 924 (2017).

5. M. Chisaka, Y. Ando and N. Itagaki, J. Mater. Chem. A 4, 2501 (2016).

6. T. C. Nagaiah, S. Kundu, M. Bron, M. Muhler and W. Schuhmann, Electrochem. Commun. 12, 338 (2010).

7. L. Hao, S. Zhang, R. Liu, J. Ning, G. Zhang and L. Zhi, Adv. Mater. 27, 3190 (2015).

8. C. Y. Su, H. Cheng, W. Li, Z. Q. Liu, N. Li, Z. Hou, F. Q. Bai, H. X. Zhang and T. Y. Ma, Adv. Energy Mater. 7, 1602420 (2017).

9. H. Cheng, M. L. Li, C. Y. Su, N. Li and Z. Q. Liu, Adv. Funct. Mater. 27, 1701833 (2017).

10. X. Zhao, M. Yin, L. Ma, L. Liang, C. Liu, J. Liao, T. Lu and W. Xing, Energy Environ. Sci. 4, 2736 (2011).

11. D. Hassen, M. A. Shenashen, S. A. El-Safty, M. M. Selim, H. Isago, A. Elmarakbi, A. El-Safty and H. Yamaguchi, J. Power Sources 330, 292 (2016).

12. S. Ratso, I. Kruusenberg, M. Vikkisk, U. Joost, E. Shulga, I. Kink, T. Kallio and K. Tammeveski, Carbon 73, 361 (2014).

13. G. L. Chai, K. P. Qiu, M. Qiao, M. M. Titirici, C. X. Shang and Z. X. Guo, Energy Environ. Sci. 10, 1186 (2017).

14. H. Cheng, J. M. Chen, Q. J. Li, C. Y. Su, A. N. Chen, J. X. Zhang, Z. Q. Liu and Y. Tong, Chem. Commun. 53, 11596 (2017).

15. Z.-S. Wu, S. Yang, Y. Sun, K. Parvez, X. Feng and K. Muellen, J. Am. Chem. Soc. 134, 9082 (2012).

16. L. Hadidi, E. Davari, D. G. Ivey and J. G. C. Veinot, Nanotechnology 28, 095707 (2017).

17. Y. Ye, L. Kuai and B. Geng, J. Mater. Chem. 22, 19132 (2012).

18. Z. Q. Liu, H. Cheng, N. Li, T. Y. Ma and Y. Z. Su, Adv. Mater. 28, 3777 (2016).
19. Z. Q. Liu, Q. Z. Xu, J. Y. Wang, N. Li, S. H. Guo, Y. Z. Su, H. J. Wang, J. H. Zhang and S. Chen, Int. J. Hydrogen Energy 38, 6657 (2013).

20. Y. Liang, Y. Li, H. Wang, J. Zhou, J. Wang, T. Regier and H. Dai, Nat. Mater. 10, 780 (2011).

21. G. Gnana kuma, M. Christy, H. Jang and K. S. Nahm, J. Power Sources 288, 451 (2015).

22. W.-H. Ryu, T.-H. Yoon, S. H. Song, S. Jeon, Y.-J. Park and I.-D. Kim, Nano Lett. 13, 4190 (2013).

23. L. Tan, Y. D. Yang, N. Li, S. Chen and Z. Q. Liu, Catal. Sci. Technol. 7, 1315 (2017).

24. H. Wang, Y. Liang, Y. Li and H. Dai, Angew. Chem. Int. Ed. 50, 10969 (2011).

25. T. Wang, D. Gao, J. Zhuo, Z. Zhu, P. Papakonstantinou, Y. Li and M. Li, Chem. -Eur. J. 19, 11939 (2013).

26. S. J. Rowley-Neale, J. M. Fearn, D. A. C. Brownson, G. C. Smith, X. Ji and C. E. Banks, Nanosacle 31, 14767 (2016).

27. L. Tan, N. Li, S. Chen and Z. Q. Liu, J. Mater. Chem. A 4, 12273 (2016).

28. H. Zhong, H. Zhang, Y. Liang, J. Zhang, M. Wang and X. Wang, J. Power Sources 164, 572 (2007).

29. S. Jing, L. Luo, S. Yin, F. Huang, Y. Jia, Y. Wei, Z. Sun and Y. Zhao, Appl. Catal. B: Environ. 147, 897 (2014).

30. D. Xia, S. Liu, Z. Wang, G. Chen, L. Zhang, L. Zhang, S. Hui and J. Zhang, J. Power Sources 177, 296 (2008).

31. S. Dong, X. Chen, K. Zhang, L. Gu, L. Zhang, X. Zhou, L. Li, Z. Liu, P. Han, H. Xu, J. Yao, C. Zhang, X. Zhang, C. Shang, G. Cui and L. Chen, Chem. Commun. 47, 11291 (2011).

32. X. T. Wu, J. C. Li, Q. R. Pan, N. Li and Z. Q. Liu, Dalton Trans. 47, 1442 (2018).

33. D. Choi, G. E. Blomgren and P. N. Kumta, Adv. Mater. 18, 1178 (2006).

34. R. Wang, J. Lang, P. Zhang, Z. Lin and X. Yan, Adv. Funct. Mater. 25, 22770 (2015).

35. J. Balamurugan, G. Karthikeyan, T. D. Thanh, N. H. Kim and J. H. Lee, J. Power Sources 308, 149 (2016).

36. X. Lu, M. Yu, T. Zhai, G. Wang, S. Xie, T. Liu, C. Liang, Y. Tong and Y. Li, Nano Lett. 13, 2628 (2013).

37. R. Lucio-Portoa, S. Bouhtiyya, J. F. Pierson, A. Morel, F. Capon, P. Boulet and T. Brousse, Electrochim. Acta 141, 203 (2014).

38. D. Kundu, F. Krumeich, R. Fotedar and R. Nesper, J. Power Sources 278, 608 (2015).

39. Q. Sun and Z. W. Fu, Electrochim. Acta 54, 403 (2008).

40. T. Z. Huang, S. Mao, G. H. Zhou, Z. H. Wen, X. K. Huang, S. Q. Ci and J. H. Chen, Nanoscale 6, 9608 (2014). 
41. J. Yin, L. Wang, C. G. Tian, T. X. Tan, G. Mu, L. Zhao and H. G. Fu, Chem. -Eur. J. 19, 13979 (2013).

42. A. M. Glushenkov, D. Hulicova-Jurcakova, D. Llewellyn, G. Q. Lu and Y. Chen, Chem. Mater. 22, 914 (2010).

43. Z. H. Wen, X. C. Wang, S. Mao, Z. Bo, H. Kim, S. M. Cui, G. H. Lu, X. L. Feng and J. H. Chen, Adv. Mater. 24, 5601 (2012).

44. L. S. Panchakarla, K. S. Subrahmanyam, S. K. Saha, A. Govindaraj, H. R. Krishnamurthy, U. V. Waghmare and C. N. R. Rao, Adv. Mater. 21, 4726 (2009).

45. K. Huang, K. Bi, C. Liang, S. Lin, R. Zhang, W. J. Wang, H. L. Tang and M. Lei, Sci. Rep. 5 (2015).

46. A. Vinu, Adv. Funct. Mater. 18, 816 (2008).

47. P. J. Hanumantha, M. K. Datta, K. S. Kadakia, D. H. Hong, S. J. Chung, M. C. Tam, J. A. Poston, A. Manivannan and P. N. Kumta, J. Electrochem. Soc. 160, A2195 (2013).
48. J. Y. Cheon, J. H. Kim, J. H. Kim, K. C. Goddeti, J. Y. Park and S. H. Joo, J. Am. Chem. Soc. 136, 8875 (2014).

49. S. Pandiaraj, H. B. Aiyappa, R. Banerjee and S. Kurungot, Chem. Commun. 50, 3363 (2014).

50. K. Lee, M. S. Ahmed and S. Jeon, J. Power Sources 288, 261 (2015).

51. G. Ren, X. Lu, Y. Li, Y. Zhu, L. Dai and L. Jiang, ACS Appl. Mater. Interfaces 8, 4118 (2016).

52. Q. Xue, Z. Pei, Y. Huang, M. Zhu, Z. Tang, H. Li, Y. Huang, N. Li, H. Zhang and C. Zhi, J. Mater. Chem. A 5, 20818 (2017).

53. Y. Yuan, L. Yang, B. He, E. Pervaiz, Z. Shao and M. Yang, Nanoscale 9, 6259 (2017).

54. X. Zhong, L. Liu, Y. Jiang, X. Wang, L. Wang, G. Zhuang, X. Li, D. Mei, J. Wang and D. S. Su, ChemCatChem 7, 1826 (2015). 